\title{
Siringoma Vulvar: Reporte de Caso y Revisión de la Literatura
}

\author{
Vulvar Syringoma: Case Report and Literature Review
}

*.*** Oscar Tapia E.; ${ }^{* * *}$ Sandra Kam C. $\&{ }^{* * * *}$ Ricardo San Martín T.

\begin{abstract}
TAPIA, E. O.; KAM, C. S. \& SAN MARTÍN, T. R. Siringoma vulvar: reporte de un caso y revisión de la literatura. Int. J. Morphol., 30(3):924-926, 2012.

RESUMEN: Se presenta el caso de una mujer de 32 años, quien consultó por presentar desde hace 6 meses nódulos múltiples y pruriginosos en ambos labios mayores, prurito que se exacerbaba durante la menstruación. El estudio anatomo-patológico demostró una proliferación dérmica de conductos pequeños revestidos por una doble capa de células cuboídeas normotípicas, y rodeados por un estroma fibroso compatibes con un siringoma.
\end{abstract}

PALABRAS CLAVE: Siringoma; Vulvar; Neoplasia anexial.

\section{INTRODUCCIÓN}

El siringoma es un tumor anexial cutáneo benigno originado en el siringio de las glándulas ecrinas. Afecta más frecuentemente a mujeres $(2: 1)$ después de la pubertad y se localiza generalmente en la zona periorbitaria, pudiendo también comprometer el cuero cabelludo, frente, cuello, tórax, axilas, abdomen y miembros; existiendo escasos reportes de compromiso genital (Huang et al.; 2003; Dereli et al.; 2007; Elder et al., 1997; Tay et al., 1996; Belardi et al.; 1994; Agrawal et al., 2004; Iwao et al.; 2005).

Dada la infrecuente localización, reportamos un caso de siringoma vulvar diagnosticado en una mujer de 32 años.

\section{REPORTE DE CASO}

Mujer de 32 años sin antecedentes mórbidos de importancia quien consultó a ginecólogo por presentar desde hace 6 meses múltiples nódulos en relación con el labio mayor derecho asociado a prurito leve que aumentaba durante la menstruación.

El examen físico demostró múltiples pápulas y placas parduscas en ambos labios mayores, sin otras lesiones asociadas (Fig. 1). Para precisar el diagnóstico de la lesión se efectuó biopsia; reconociendose a nivel dérmico una proliferación de pequeños conductos de tipo ecrino rodeados por un estroma fibroso, algunos conductos con prolongaciones terminales que semejaban una "coma" y revestidos por una doble capa de células cuboídeas, sin atipías ni actividad mitótica (Fig. 2).

\section{DISCUSIÓN}

Esta neoplasia fue descrita por primera vez por Kaposi (1874) denominándola linfangioma tuberosum multiplex, demostrándose posteriormente mediante estudios de inmunohistoquímica y microscopía electrónica su origen en glándulas sudoríparas ecrinas (Hashimoto et al., 1966).

Estos tumores son más comunes en las mujeres, después de la pubertad ( $3^{\circ}$ década) y afectando típicamente la cara; describiéndose una mayor frecuencia en mujeres orientales y pacientes con síndrome de Down (Huang et al.; Elder et al.; Martinez et al., 2006; Schepis et al., 1994). El compromiso genital por su parte representa una condición infrecuente que puede manifestarse en forma aislada o asociada a lesiones extra-genitales (Huang et al.; Dereli et al.; Miranda et al., 2002). El $61 \%$ de los casos de localización vulvar

\footnotetext{
* Departamento de Anatomía Patológica. Facultad de Medicina, Universidad de La Frontera, Temuco, Chile.

** BIOREN-CEGIN.

*** Residente Dermatología, Pontificia Universidad Católica de Chile, Santiago, Chile.

***** Ginecólogo, Clínica Alemana-Temuco, Chile.
} 


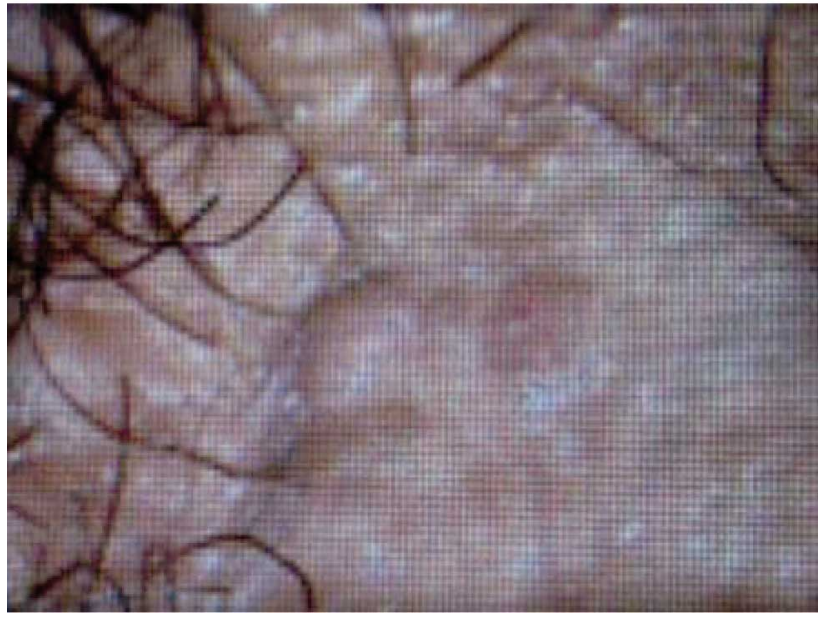

Fig. 1. Múltiples pápulas y placas parduscas en labio mayor.

se presenta como múltiples pápulas de color piel distribuídas simétricamente en los labios mayores. El $72 \%$ de las pacientes refiere prurito, observándose hasta en el $39 \%$ de ellas exacerbación o aumento de tamaño de las lesiones durante la menstruación o embarazo; razón por la cual ciertos autores han sugerido una probable relación hormonal, sin embargo, estudios de inmunohistoquímica para receptores de estrógenos y progesterona en lesiones genitales han mostrado resultados contradictorios (Huang et al.; Wallace \& Smoller, 1995; Garau et al., 1986; Hodgins et al., 1998; Trager et al., 1999). El caso reportado se presentó como pápulas pruriginosas múltiples ubicadas en ambos labios mayores, refiriendo la paciente aumento del prurito en los días de la menstruación; sin observarse positividad para receptores de estrógenos y progesterona en el estudio inmunohistoquímico de la muestra vulvar.

El examen histopatológico de las lesiones demuestra en la dermis superior una proliferación de conductos pequeños de tipo ecrino rodeados por un estroma fibroso, algunos de los cuales presentan prolongaciones que semejan una coma y otros con dilataciones microquísticas rellenos por material eosinófilo. El revestimiento epitelial esta dado por una doble capa de células cuboídeas, que carecen de atipías y actividad mitótica (Huang et al.; Dereli et al.; Elder et al.; Miranda et al.).

A pesar de su baja frecuencia, esta lesión debe considerarse en el diagnóstico diferencial de otras lesiones genitales tales como quiste epidérmico, esteatocistomas múltiples, linfangioma circumstriptum, liquen simple crónico, angioqueratomas, enfermedad de Fox-Fordyce, angioma senil, condiloma acuminado, candidiasis, escabiosis, pediculosis, dermatitis de contacto alérgica, psoriasis y liquen escleroso y atrófico.
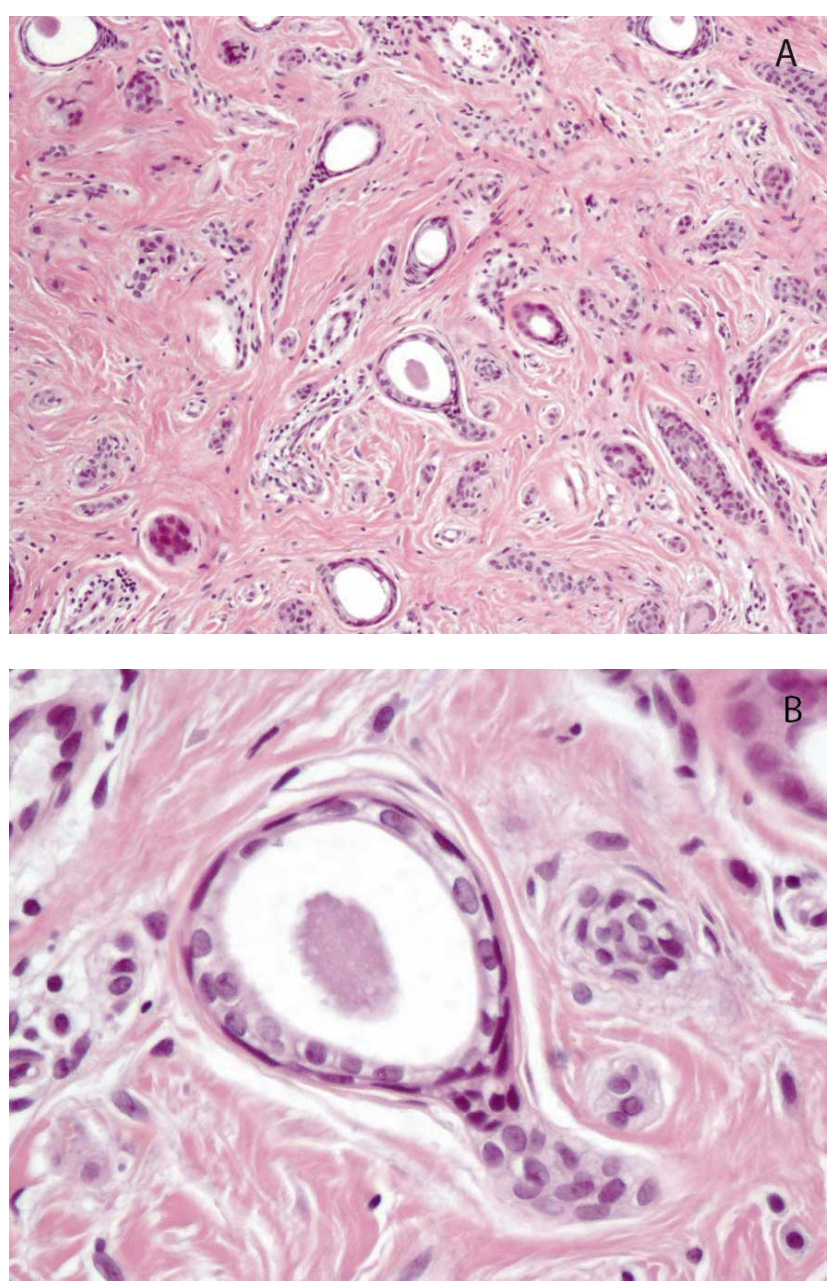

Fig. 2. Proliferación dérmica compuesta por pequeños conductos algunos con prolongaciones terminales en forma de "coma". El revestimiento epitelial es normotípico y el estroma que los rodea fibroso. A (H-E, 100x) y B (H-E, 400x).

Las opciones de tratamiento de esta neoplasia son variadas y consideran la resección, crioterapia, electrocirugía y tratamiento con láser de dióxido de carbono, reportándose en la literatura como poco efectivos el uso de esteroides tópicos y antihistamínicos orales para el control del prurito; mientras que por el contrario la atropina y tretinoína tópica se han utilizado con buenos resultados (Huang et al.; Martínez et al.; Miranda et al.; Yorganci et al., 2000; Belardi et al.; Zhu, 1989; Tay et al.; Dereli et al.).

En conclusión, la localización vulvar representa una infrecuente forma de presentación de esta neoplasia anexial que se manifiesta clínicamente como pápulas múltiples que pueden ser pruriginosas; siendo importante efectuar un cuidadoso examen del resto del cuerpo dado que hasta $1 / 3$ de las pacientes presenta conjuntamente lesiones extragenitales, típicamente en la zona peri-orbitaria. 
TAPIA, E. O.; KAM, C. S. \& SAN MARTíN, T. R. Vulvar syringoma: case report and literature review. Int. J. Morphol., 30(3):924926, 2012.

SUMMARY: We report a case of a 32 year-old woman, who consulted to present for 6 months and multiple and itchy nodules in both labia majora, itching that was exacerbated during menstruation. The pathological study showed a dermal proliferation of small ducts lined by a double layer of normotipic cuboidal cells, and surrounded by a fibrous stroma compatibes a syringoma.

KEY WORDS: Syringoma; Vulvar; Adnexal neoplasm.

\section{REFERENCIAS BIBLIOGRÁFICAS}

Agrawal, S.; Kulshrestha, R.; Rijal, A. \& Sidhu, S. Localized vulvar syringoma causing vulvar pruritus and venerophobia. Australas J. Dermatol., 45(4):236-7, 2004.

Belardi, M. G.; Maglione, M. A.; Vighi, S. \& di Paola, G. R. Syringoma of the vulva. A case report. J. Reprod. Med., 39(12):957-9, 1994

Dereli, T.; Turk, B. G. \& Kazandi, A. C. Syringomas of the vulva. Int. J. Gynaecol. Obstet., 99(1):65-6, 2007.

Elder, D.; Elenitsas, R. \& Ragsdale, B. D. Tumors of the epidermal appendages. In: Elder, D.; Elenitsas, R.; Jaworsky, C. \& Johnson, B. Jr. (Eds.). Lever's histopathology of the skin. Philadelphia, Lippincott-Raven, 1997. pp.778-9.

Garau, J. M.; di Paola, G. R. \& Charreau, E. H. Estrogen and progesterone receptor assays on the vulvar epithelium. $J$. Reprod. Med., 31(10):987-91, 1986.

Hashimoto, K.; Gross, B. G. \& Lever, W. F. Syringoma: histochemical and electron microscopy studies. J. Invest. Dermatol., 46(2):150-66, 1966.

Hodgins, M. B.; Spike, R. C.; Mackie, R. M. \& MacLean, A. B. An immunohistochemical study of androgen, oestrogen and progesterone receptors in the vulva and vagina. Br. J. Obstet. Gynaecol., 105(2):216-22, 1998.

Huang, Y. H.; Chuang, Y. H.; Kuo, T. T.; Yang, L. C. \& Hong, H. S. Vulvar syringoma: a clinicopathologic and immunohistologic study of 18 patients and results of treatment. J. Am. Acad. Dermatol., 48(5):735-9, 2003.

Iwao, F.; Onozuka, T. \& Kawashima, T. Vulvar syringoma successfully treated with tranilast. Br. J. Dermatol., 153(6):1228-30, 2005.

Kaposi, M. Hebra diseases of the skin. Lymphangioma Tuberosum Multiplex. London, The New Sydendham Society, 1874. pp.3:386.

Martínez, E.; Rebollo, N.; Vega, M. \& Arenas, R. Siringomas vulvares: informe de dos casos. Ginecol. Obstet. Mex., 74(5):273-6, 2006.
Miranda, J.; Shahabi, S.; Salih, S. \& Bahtiyar, O. Vulvar syringoma, report of a case and review of the literature. Yale J. Biol. Med., 75(4):207-10, 2002.

Schepis, C.; Siragusa, M.; Palazzo, R.; Ragusa, R. M.; Massi, G. \& Fabrizi, G. Palpebral syringomas and Down's syndrome. Dermatology, 189(3):248-50, 1994.

Tay, Y. K.; Tham, S. N. \& Teo, R. Localized vulvar syringomas-an unusual cause of pruritus vulvae. Dermatology, 192(1):62-3, 1996.

Trager, J. D.; Silvers, J.; Reed, J. A. \& Scott, R. A. Neck and vulvar papules in an 8-year-old girl. Arch. Dermatol., 135(3):203, 206, 1999.

Wallace, M. L. \& Smoller, B. R. Progesterone receptor positivity supports hormonal control of syringomas. J. Cutan. Pathol., 22(5):442-5, 1995.

Yorganci, A.; Kale, A.; Dunder, I.; Ensari, A. \& Sertcelik, A. Vulvar syringoma showing progesterone receptor positivity. $\mathrm{Br} . J$. Obstet. Gynaecol., 107(2):292-4, 2000.

Zhu, W. Y. Vulvar syringoma associated with epidermal cyst. Int. J. Dermatol., 28(2):142-3, 1989.

Dirección de correspondencia:

Dr. Oscar Tapia E.

Departamento de Anatomía Patológica

Facultad de Medicina

Universidad de La Frontera

Manuel Montt 112

Código Postal 478-1176

Temuco

CHILE

Fono: $045-296530$

Email: otescalona@gmail.com

Recibido : 25-07-2012

Aceptado: 23-08-2012 